\title{
O Uso da Linguagem como Prática de Liberdade: uma Proposta Dialógica de Ensino de Língua Portuguesa na EJA Prisional
}

\author{
El Uso del Lenguaje como Práctica de la Libertad: una Propuesta Dialógica \\ para la Enseñanza del Idioma Portugués en la Cárcel EJA
}

\author{
The Use of Language as a Practice of Freedom: a Proposal of Dialogical \\ Portuguese Language Teaching for EJA in Prision
}

\author{
Renata Faria Amaro da Silva da Rosa ${ }^{1}$
}

\begin{abstract}
Resumo
Os debates sobre linguagem, no âmbito acadêmico, suscitam reflexões acerca das práticas de ensino de língua portuguesa na escola, principalmente no que se refere à relação do que se ensina com o que se utiliza no meio social. Considerando o ensino de língua portuguesa no âmbito prisional, essas reflexões são ainda mais significativas, já que a educação geralmente ocupa um lugar pouco privilegiado entre as atividades propostas para a ressocialização. Nessa perspectiva, questiona-se: as práticas educativas têm atendido às necessidades dos educandos privados de liberdade? Será que encarcerado percebe o uso da linguagem como prática de liberdade nas aulas de língua portuguesa? Nesse sentido, o artigo tem por finalidade discutir a importância do ensino de língua portuguesa na Educação de Jovens e Adultos (EJA) nas prisões. Fundamentado nas ideias de educação libertadora de Paulo Freire e na teoria dialógica de Mikhail Bakhtin, este estudo apresenta um panorama sobre a educação nas prisões no Brasil, uma reflexão sobre o uso da linguagem como prática libertadora, alguns aspectos sobre os estudos bakhtinianos e também a relação entre gêneros discursivos e ensino de língua portuguesa. Através deste, espera-se estar contribuindo para o aprimoramento do ensino de língua portuguesa na EJA prisional, demonstrando a relevância do trabalho com gêneros discursivos para o uso da linguagem como prática libertadora.
\end{abstract}

Palavras-chave: Educação libertadora; EJA prisional; Ensino de Língua Portuguesa; Teoria Dialógica.

\section{Resumen}

Debates sobre el lenguaje en el ámbito académico, plantean reflexiones sobre las prácticas de enseñanza del idioma portugués en la escuela, especialmente en lo que respecta a la relación entre lo que se enseña a lo que se utiliza en el entorno social. Teniendo en cuenta la enseñanza de la lengua portuguesa en el contexto penitenciario, estas reflexiones son aún más significativo, ya que la educación general toma un pequeño lugar privilegiado entre las actividades propuestas para la rehabilitación. En esa perspectiva, se cuestiona: ¿las prácticas educativas han cumplido las necesidades de los educandos privados de libertad? No encarcelado darse cuenta de la utilización del lenguaje como una práctica de libertad en clases de portugués? En este sentido, el artículo tiene como objetivo discutir la importancia de la enseñanza del idioma Inglés en la Educación de Jóvenes y Adultos (EJA) en las cárceles. En este estudio se presenta un panorama sobre la educación en las cárceles en Brasil, una reflexión sobre el uso del lenguaje como práctica liberadora, algunos aspectos sobre los estudios bakhtinianos y también la de la literatura liberadora de Paulo Freire y en la teoría dialógica de Mijaíl Bakhtin, relación entre los géneros discursivos y la enseñanza del idioma portugués. A través de esto, se espera que esté contribuyendo a la mejora de la enseñanza del idioma portugués en la cárcel EJA, lo que demuestra la importancia del trabajo con los géneros de discurso a la utilización del lenguaje como una práctica liberadora.

Palabras clave: Educación liberadora; EJA en prisión; Enseñanza de la Lengua Portuguesa; la Teoría Dialógica.

\footnotetext{
${ }^{1}$ Doutoranda em Letras; Pontifícia Universidade Católica do Rio Grande do Sul; Porto Alegre, Rio Grande do Sul, Brasil; renata.faria@acad.pucrs.br
} 


\begin{abstract}
Debates about language, in the academic ambit, reflections about the Portuguese language teaching practices in school, especially with regard to the relationship of what is taught to what is used in the social environment. Considering the Portuguese language teaching in the prison context, these reflections are even more significant, since education usually takes a little privileged place among the activities proposed for the rehabilitation. From this perspective, the question is: have the educational practices being meeting the needs of students deprived of freedom? Does the imprisoned notice the use of language as a practice of freedom in the Portuguese language classes? In this sense, the article aims to discuss the importance of English language teaching in the Youth and Adult Education (EJA) in prisons. Based on the ideas of liberating education of Paulo Freire and dialogical theory of Mikhail Bakhtin, this study presents an overview of education in prisons in Brazil, a reflection on the use of language as a liberating practice, some aspects on Bakhtinian studies and also the relationship between genres and Portuguese language teaching. Through this, we expect to be contributing to the improvement of the Portuguese language teaching for EJA in prison, demonstrating the relevance of the work with discursive genres for the use of language as a liberating practice.
\end{abstract}

Keywords: liberating Education; EJA in prison; Portuguese L²anguage Teaching; Dialogic Theory.

\title{
1.Introdução
}

O que se ensina nas aulas de língua portuguesa? Assumindo o posicionamento de Saussure no Curso de Linguística Geral $^{3}$ de que é o ponto de vista que cria o objeto, parece relevante refletir sobre o que se ensina a partir da visão sobre o que se entende por ensino ou estudo de língua nas aulas de português. Contextualizando essa afirmativa, Batista (apud MARCUSCHI, 2008) comenta que a alteração sobre esse ponto de vista explica as mudanças no ensino de português ao longo da história, o que é percebido através da modificação do nome da disciplina: Gramática Nacional, Língua Pátria, Idioma Nacional ou Português.

Essa mesma perspectiva conduz as práticas educativas, que apresentam diferentes concepções sobre o que é ensino de língua e seus objetivos. Consoante Bezerra (2010), o ensino de língua portuguesa no Brasil é tradicionalmente voltado para o ensino da gramática normativa, priorizando o estudo de regras, como tipo de concordância verbal e nominal, funções analíticas dos termos da oração e elementos morfológicos das palavras.

Nesse sentido, percebe-se que a visão de grande parte dos educadores sobre o ensino de língua é um tanto equivocada, uma vez que a prática educativa não está relacionada à concepção de linguagem como interação social, dificultando o reconhecimento por parte do

\footnotetext{
${ }^{2}$ O presente trabalho foi realizado com apoio da Coordenação de Aperfeiçoamento de Pessoal Nivel Superior Brasil (CAPES) - Código de Financiamento 001.

El presente trabajo fue realizado con apoyo de la Coordinación de Perfeccionamiento de Personal Nivel Superior - Brasil (CAPES) - Código de Financiamiento 001.

This study was financed in part by the Coordenação de Aperfeiçoamento de Pessoal de Nivel Superior - Brasil (CAPES) - Finance Code 001.O presente trabalho foi realizado com apoio da Coordenação de Aperfeiçoamento de Pessoal Nivel Superior - Brasil (CAPES) - Código de Financiamento 001.
} 
educandos da relevância do ensino escolar para as ações reais do cotidiano. Em contrapartida, criticando esse modo de ensino de língua, Paulo Freire, um dos maiores intelectuais latinoamericanos do século XX, educador e criador de um método de alfabetização para adultos e de uma teoria _ a Educação Popular, comenta que linguagem e realidade são indissociáveis, de forma que a compreensão de um texto requer uma leitura crítica que envolve a percepção das relações entre texto e contexto (FREIRE, 2011).

Em Pedagogia do Oprimido ${ }^{4}$, Freire compara as práticas educativas centradas na memorização mecânica de conteúdos e desconectadas da realidade ao ato de depositar, definindo-as como educação bancária. Trata-se, então, de uma educação na qual o educando não é encorajado a pensar criticamente sobre sua condição de oprimido, tornando-o inapto a lutar pela própria liberdade, pois não reflete sobre a realidade vivida e não se torna capaz de pensar sobre as mudanças necessárias para a busca da transformação.

O conceito de oprimido na concepção freiriana está associado à ideia de classes sociais, uma vez o sujeito relaciona-se enquanto classe de oprimidos e classe de opressores (FREIRE, 2002, apud Oliveira, 2008). Trata-se de classes constituídas por assistidos, marginalizados, que diferem da fisionomia geral da sociedade, representando a patologia da sociedade sã. Logo, a sociedade precisa ajudá-los. Para isso, propõe a mudança de mentalidade dos oprimidos a fim de ajustá-los à mentalidade da sociedade (FREIRE, 2014).

Ao contrário da educação bancária, na concepção de educação libertadora ou problematizadora, conceito forjado por Freire, a educação compreende uma prática de humanização, que implica reflexão do homem sobre o mundo, resultando na mudança da realidade, através de sua relação ação-reflexão-ação. Trata-se de uma ação política com vistas a uma ação cultural para a liberdade, fazendo com que o educando transforme-se em um indivíduo ativo e responsável, capaz de, junto com o educador, ser sujeito no processo de construção do conhecimento e de transformação da realidade.

Haja vista tal relação entre ensino de língua portuguesa na escola e as ideias de Paulo Freire sobre educação libertadora, o artigo propõe discutir a importância do ensino de língua portuguesa na Educação de Jovens e Adultos presente nos espaços prisionais a partir da valorização da linguagem como interação social. Embora se reconheça a importância de práticas de educação libertadora no processo de ensino em todas as disciplinas, este trabalho enfatiza o ensino de língua portuguesa por considerar que o bom desenvolvimento nesta

${ }^{4}$ FREIRE, Paulo. Pedagogia do Oprimido. 58 Ed. Rio de Janeiro: Paz e Terra, 2014. 
resulta no melhor desempenho do educando nas demais áreas do conhecimento. Isso porque o uso da linguagem é fundamental para a própria construção do sujeito e para sua interação com a sociedade. Nesse viés, este estudo sugere práticas de ensino de língua nas prisões voltadas ao uso da linguagem como meio de interação social.

A educação nas prisões percorre um longo caminho na busca do reconhecimento de sua valia como meio de reinserção social. Especificamente no Brasil, há documentos legais que amparam o indivíduo privado de liberdade de ter acesso à educação, como a Constituição da República Federativa do Brasil de 1988, Lei de Diretrizes e Bases da Educação Nacional 9394/96 e Lei de Execução Penal No 7.210 de 11/07/1984. Não obstante, é notável a existência de barreiras que afastam os encarcerados dos bancos escolares.

Apesar de o Departamento Penitenciário Nacional (DEPEN) ${ }^{5}$ identificar que a maior parte da massa carcerária não concluiu nem o ensino fundamental, o Conselho Nacional de Educação (CNE) ${ }^{6}$, após um levantamento sobre a escolaridade dos presidiários no País, apontou que apenas um em cada dez presos brasileiros participa de atividades educacionais ofertadas nas prisões. Buscando ressignificar o valor da educação para os presos, foram traçadas diretrizes para viabilizar ensino de qualidade, respeitando as idiossincrasias do âmbito prisional, e o benefício de remição de pena pelo estudo.

A Resolução no 2 do Conselho Nacional de Educação/ Câmara de Educação Básica de 19 de maio de 2010 (CNE/CEB de 2010) ${ }^{7}$ aponta garantias como oferta de espaços físicos adequados às atividades educacionais, provimento de materiais didáticos destinados a EJA, entre outros. Todavia, na prática, a maioria dessas garantias não sai do papel, mormente pela falta de investimentos financeiros e pelo grande contingente de pessoas que superlota as prisões, dificultando o atendimento adequado a todos. Agregando a isso, percebe-se que as práticas pedagógicas comumente desenvolvidas nas prisões pouco colaboram para a reabilitação do indivíduo preso, no sentido de desenvolver suas habilidades para que tenham melhores oportunidades futuras, sendo este um dos principais motivos pelos quais os presos não se interessam pelas atividades educativas.

Diante disso, este artigo propõe o ensino de língua portuguesa através do trabalho com gêneros discursivos na EJA prisional, o que corrobora com a concepção libertadora de

\footnotetext{
${ }^{5}$ BRASIL/MINISTÉRIO DA JUSTIÇA. Levantamento Nacional de Informações Penitenciárias - INFOPEN junho de 2014. Disponível em: http://www.justica.gov.br/noticias/mj-divulgara-novo-relatorio-do-infopen-nestaterca-feira/relatorio-depen-versao-web.pdf Acesso em 20.09.2015.

${ }^{6}$ PORTAL BRASIL - EDUCAÇÃO. Levantamento mostra escolaridade dos presidiários no País. Disponível em:http://www.brasil.gov.br/educacao/2012/04/levantamento-mostra-escolaridade-dos-presidiarios-no-pais Acesso em: 16.08. 2015.

${ }^{7}$ Resolução $n^{\circ} 2$ do Conselho Nacional de Educação/ Câmara de Educação Básica de 19 de maio de 2010, publicada no Diário Oficial da União, Brasília, 20 de maio de 2010, Seção 1, p. 20.
} 
educação. Os gêneros discursivos emergem da teoria enunciativa dialógica desenvolvida por Bakhtin, que destaca a análise do texto e do discurso por meio da descrição da língua e da visão social, para entender a natureza sociocultural no uso da língua de maneira ampla.

Nessa perceptiva, Bakhtin entende que a enunciação compõe-se de enunciados, sejam orais ou escritos, através do emprego da língua pelos falantes. Esses enunciados expressam condições e finalidades específicas de cada campo da esfera comunicativa, refletindo as estruturas sociais recorrentes e típicas de cada cultura. Esses tipos de enunciados, que são relativamente estáveis, foram denominados como gênero do discurso (BAKHTIN, 2003).

Nos Parâmetros Curriculares Nacionais (2000), os gêneros do discurso são denominados como gêneros textuais, caracterizados como formas relativamente estáveis de enunciados disponíveis na cultura. Os gêneros textuais configuram o caráter dialógico da linguagem, cuja relação exprime o valor da linguagem - língua e fala - como interação social. Logo, entende-se que o ensino de língua portuguesa deve primar pelo domínio linguístico oral e escrito que representem situações reais de uso público da linguagem, considerando a situação de produção social e material do discurso, nas dimensões pragmática, semântica e gramatical.

Fundamentado em pesquisa bibliográfica, o artigo foi organizado em cinco capítulos. O primeiro capítulo apresenta um panorama sobre a educação nas prisões no Brasil, delineando alguns avanços e empecilhos que envolvem o desenvolvimento das práticas educativas nos espaços de privação de liberdade. O segundo capítulo trata sobre ensino de língua com base nas reflexões de Paulo Freire sobre educação libertadora. O terceiro aborda alguns aspectos sobre a teoria enunciativa dialógica de Bakhtin e os gêneros discursivos.

O quarto capítulo discorre sobre a relação entre gêneros discursivos e ensino de língua portuguesa. Por fim, o quinto apresenta atividades de leitura e de produção textual que foram desenvolvidas no Curso de Formação de Agentes Penitenciários do Estado do Rio Grande do Sul, no ano de 2014.

Trata-se, portanto, de uma proposta que serve como sugestão de como trabalhar gêneros discursivos nas aulas de língua portuguesa, considerando a necessidade de adequações à realidade dos educandos presos. Diante do exposto, espera-se que este estudo possa contribuir para o aperfeiçoamento do ensino de língua portuguesa na EJA prisional, de forma que as reflexões impressas apontem a significância do trabalho com gêneros discursivos para a percepção do uso da linguagem como prática libertadora.

\section{A educação nas prisões}


A educação ocupa um lugar de suma importância na sociedade no sentido de viabilizar meios que contribuam para o desenvolvimento humano dos indivíduos. Os valores éticos e morais envolvidos no processo de ensino-aprendizagem influenciam na construção do sujeito como cidadão. Por conseguinte, essa é a razão pela qual a educação é um direito de todo o ser humano, livre ou aprisionado, e responsabilidade do Estado, da família e da sociedade de garantir o cumprimento desse direito. A respeito disso, no Art. 205 da Constituição Federal (CF), diz que

a educação, direito de todos e dever do Estado e da família, será promovida e incentivada com a colaboração da sociedade, visando ao pleno desenvolvimento da pessoa, seu preparo para o exercício da cidadania e sua qualificação para o trabalho. (BRASIL/ CONSTITUIÇÃO FEDERAL, 1988).

A Lei de Diretrizes e Bases da Educação Nacional (LDBEN) no 9.394/96, no Art. $2^{\circ}$, também dispõe sobre a importância da educação para o desenvolvimento da pessoa ao definir que "a educação, dever da família e do Estado, inspirada nos princípios de liberdade e nos ideais de solidariedade humana, tem por finalidade o pleno desenvolvimento do educando, seu preparo para o exercício da cidadania e sua qualificação para o trabalho". Mais que isso, a CF e a LDB asseguram o direito ao acesso à educação em idade própria e à igualdade de condições para o acesso e permanência na escola.

Não obstante, a dificuldade de os jovens permanecerem na escola até o término da educação básica demonstra que as leis nem sempre são cumpridas. Essa realidade deve-se, na maioria dos casos, a fatores relacionados à desigualdade social. Crianças e jovens que vivem na mais extrema pobreza veem-se obrigados a ajudar no sustento ou até mesmo sustentar a família, o que dificulta seu desempenho nos estudos e permanência na escola, resultando em sua exclusão. Em consequência disso, aumentam as estatísticas de pessoas de baixa escolaridade, as quais vivem com o necessário ou nem isso. Diante da dificuldade de sobrevivência, da falta de perspectiva e de apoio assistencial, muitas dessas pessoas buscam melhores condições de vida por meio de atos ilícitos, caracterizando, assim, o perfil da massa carcerária brasileira.

Em 2012, foi feito um levantamento sobre o perfil dos presos no Brasil ${ }^{8}$, junto ao Infopen $^{9}$ e ao Ministério da Justiça. Quanto ao nível de escolaridade, a pesquisa apontou que $50,5 \%$ dos presos tinham Ensino Fundamental Incompleto, 14\% eram alfabetizados, 13,6\% tinham Ensino Fundamental Completo, 8,5\% concluíram o Ensino Médio, 6,1\% eram

\footnotetext{
${ }^{8}$ JUSBRASIL. Perfil dos presos no Brasil em 2012. Disponível em: http://professorlfg.jusbrasil.com.br/artigos/121932332/perfil-dos-presos-no-brasil-em-2012 Acesso em 23.08.2015.

${ }^{9}$ Sistema de informações penitenciárias.
} 
analfabetos, 1,2\% tinham Ensino Médio Incompleto, 0,9\% chegaram à universidade sem concluir, 0,04\% concluíram o Ensino Superior e 0,03\% chegaram a um nível acima de Superior completo.

No Brasil, a assistência educacional para presos é um direito que aparece de modo explícito nos documentos legais desde 1984, com a Lei de Execução Penal Lei de Execução Penal (LEP) n. ${ }^{\circ}$ 7.210/1984. A LEP garante a oferta de instrução escolar e formação profissional nos espaços de privação de liberdade. Na esfera internacional, no ano de 1997, a questão da educação de presos recebeu destaque em ocasião da V Conferência Internacional de Educação (V CONFINTEA) ${ }^{10}$, por meio do VIII desta conferência, que teve como tema "A educação para todos os adultos: os direitos e aspirações dos diferentes grupos" (parágrafo 47). Porém, foi partir de 2005 que se iniciou a consolidação de propostas de políticas públicas para a educação de presos tanto na esfera nacional quanto internacional.

Em setembro de 2005, os Ministérios da Educação e da Justiça firmaram um protocolo de intenções, de onde partiram diversas ações, tais como: resoluções do Programa Brasil Alfabetizado que incluíram a população prisional entre o público de atendimento diferenciado das ações de alfabetização, inclusão da educação como uma das metas do Programa Nacional de Segurança Pública com Cidadania, inclusão da educação nas prisões no Plano de Desenvolvimento da Educação (PDE), entre outras. (BRASIL/MINISTÉRIO DA EDUCAÇÃO/MEC, SEB, DICEI, 2013). Nos anos seguintes, outras ações foram efetivadas.

Entre as ações, cabe salientar as Diretrizes Nacionais para a Oferta de Educação para Jovens e Adultos em Situação de Privação de Liberdade nos Estabelecimentos Penais, conforme parecer homologado pelo Ministério da Educação, no ano de 2010 (Parecer CNE/CEB $n^{\circ}$ 04/2010), cuja política de educação nas prisões é tratada de modo mais detalhado. A importância da existência dessa política para a educação nas prisões deve à necessidade de uma orientação nacional, evitando ofertas pontuais ou dissociadas de orientação pública.

Desde então, a educação escolar assume um lugar de destaque entre as atividades ofertadas nas prisões. A oferta de programas educativos nas prisões apresenta três objetivos imediatos que vão ao encontro da finalidade da justiça penal. São estes:

(1) manter os reclusos ocupados de forma proveitosa; (2) melhorar a qualidade de vida na prisão; e (3) conseguir um resultado útil, tais como ofícios, conhecimentos, compreensão, atitudes sociais e comportamento, que perdurem além da prisão e

\footnotetext{
10 SESI/UNESCO. Conferência Internacional sobre Educação de Adultos (V; 1997; Hamburgo; Alemanha) Declaração de Hamburgo: Agenda para o futuro. - Brasília: SESI/UNESCO, 1999. Disponível em: http://unesdoc.unesco.org/images/0012/001297/129773porb.pdf Acesso em: 24.08.2015.
} 
permitam ao apenado o acesso ao emprego ou a uma capacitação superior, que, sobretudo, propicie mudanças de valores, pautando-se em princípios éticos e morais. (MINISTÉRIO DA EDUCAÇÃO/CNE/CEB nº 04/2010, 2013, p. 319).

O Parecer CNE/CEB $\mathrm{n}^{\circ} 04 / 2010$ assinala mudanças bastante significativas na educação das prisões, no sentido de adequar o ensino de presos às mesmas regras da Educação de Jovens e Adultos ofertadas nos espaços extramuros. Acerca disso, o Artigo $2^{\circ}$ do Parecer enuncia

\begin{abstract}
As ações de educação em contexto de privação de liberdade devem estar calcadas na legislação educacional vigente no país, na Lei de Execução Penal, nos tratados internacionais firmados pelo Brasil no âmbito das políticas de direitos humanos e privação de liberdade, devendo atender às especificidades dos diferentes níveis e modalidades de educação e ensino e são extensivas aos presos provisórios, condenados, egressos do sistema prisional e àqueles que cumprem medidas de segurança. (BRASIL/MINISTÉRIO DA EDUCAÇÃO/CNE/CEB nº 04/2010, apud BRASIL/MINISTÉRIO DA EDUCAÇÃO/MEC, SEB, DICEI, 2013, p. 334).
\end{abstract}

Além dessa, outras resoluções foram acordadas, tais como a existência de espaços físicos adequados às atividades educacionais, esportivas, culturais, de formação profissional e de lazer, integrando-as às rotinas dos estabelecimentos penais, entre outras.

Embora se reconheçam os esforços do Estado em promover a educação nas prisões, buscando transformar o caráter punitivo do sistema prisional brasileiro, observa-se que, na prática, existem muitos entraves que dificultam a educação de presos. Um dos principais problemas está na falta de interesse dos presos em participar das atividades educativas, mesmo que haja o benefício de remição de pena. De acordo com a Lei $n^{\circ} 12.433$, de 29 de junho de 2011, foi estabelecido, no Art. 126, que "o condenado que cumpre a pena em regime fechado ou semiaberto poderá remir, por trabalho ou por estudo, parte do tempo de execução da pena".

Haja vista que o benefício abrange tanto as atividades educativas quanto as laborais, percebe-se maior adesão dos presos a estas. Isso porque, além da remição, há um retorno financeiro. Consoante Lemgruber, o fato de existirem atividades educativas nas prisões não é garantia da participação dos presos porque

\footnotetext{
a escola, que teoricamente seria um veículo de mobilidade social, não surte os efeitos esperados. Currículos tradicionais, aliados a um quadro de professores que aparentemente não estão treinados para o desempenho de suas tarefas, jamais provocarão atitudes positivas por parte dos internos. (LEMGRUBER, 1999, p. 87, apud BRASIL/MINISTÉRIO DA EDUCAÇÃO/ MEC, SEB, DICEI, 2013, p. 323).
}

Tal ponto de vista desperta para observação de uma contradição entre teoria e prática na EJA prisional. Isso porque diretrizes e leis apontam para a efetivação de uma educação compatível com as necessidades dos presos, cujas deficiências educacionais não foram sanadas no período em que estiveram fora da prisão. Trata-se de uma educação que contribua 
para a formação desse indivíduo encarcerado no sentido de promover sua libertação. Associando isso às ideias de Paulo Freire, entende-se que a Educação de Jovens e Adultos privados de liberdade deve ser pensada como um meio de desenvolvimento da conscientização e da autonomia do ser humano, o que certamente não é possível através do uso de métodos e currículos tradicionais.

Através do percurso apresentado sobre a educação nas prisões brasileiras, é essencial que se reflita sobre a prática educativa nos espaços prisionais. Afinal, quais são as práticas educativas desenvolvidas para que ocorra a aprendizagem? "Escrevam pedagogias e não sobre pedagogias" (FREIRE, 2003, p. 34). As palavras de Freire parecem indicar o caminho para uma resposta, pois orientam a criação de métodos e técnicas que atendam a pluralidade dos educandos, bem como valorizem suas experiências. Em face do exposto, é necessário compreender qual o sentido da educação nas prisões para que, a partir disso, seja criada uma pedagogia para a libertação e não para a opressão.

\section{O uso da linguagem como prática de liberdade}

Os aspectos abordados anteriormente colocam as práticas educativas no centro da discussão sobre a educação nas prisões. Isso porque se entende que somente a mudança no sistema de ensino não é capaz de sanar todas as mazelas que afastam os indivíduos privados de liberdade dos bancos escolares, todavia esse caminho parece o mais simples de se percorrer nesse sentido. Por conseguinte, este capítulo aponta algumas das reflexões de Paulo Freire sobre a educação como prática de liberdade no intuito de se reconhecer o valor das práticas educativas desenvolvidas nos espaços prisionais para a ressocialização de presos.

Nessa perspectiva, a educação deve promover a construção da identidade do indivíduo privado de liberdade, já que o aprisionamento tende a oprimir sua individualidade, levando-o a um processo de institucionalização. Para que isso aconteça, a educação deve ser entendida como sinônimo de transformação social, partindo do princípio de que o indivíduo preso não é um mero reservatório, depósito de conteúdos, mas sujeito construtor da própria história e, em consequência, capaz de problematizar suas relações com o mundo.

As reflexões de Freire são bastante pertinentes no que diz respeito às questões de educação prisional, não apenas pela sua experiência como educador, mas também pela sua vivência na prisão durante o período em que esteve no exílio. Durante esse tempo, o educador escreveu Educação como prática de liberdade, cujas ideias projetaram-se por todo o Brasil (WEFFORT, apud FREIRE, 1967). 
A educação como prática de liberdade está relacionada a uma pedagogia do oprimido, sendo este também título de uma de suas principais obras. A Pedagogia do Oprimido referese à pedagogia oriunda da sociedade na qual a dinâmica estrutural propõe a dominação de consciências, compreendendo a pedagogia das classes dominantes (FIORI, apud FREIRE, 2014), estando atrelada aos interesses de grupos dominantes. Logo, uma cultura de dominação é incompatível com uma educação libertadora. Acerca disso, Fiori explica que "a prática da liberdade só encontrará adequada expressão numa pedagogia em que o oprimido tenha condições de, reflexivamente, descobrir-se e conquistar-se como sujeito de sua própria destinação histórica" (apud FREIRE, 2014, p. 11).

Na concepção de Freire, a prática de liberdade condiz com uma prática educativa que promova a participação livre e crítica dos educandos no processo de ensino-aprendizagem, cujo princípio norteia a estruturação do Círculo de Cultura, unidade de ensino que substitui a “escola", autoritária por estrutura e tradição (WEFFORT apud FREIRE, 1967).

Consoante Brandão (2008), os Círculos de Cultura representam as experiências de trabalhos em grupo voltadas para uma educação centrada no aluno e os projetos de pesquisa de ação social, tendo como finalidade dispersar os modelos que representam a ação e a gestão coletivizada e consensual do poder. Norteados pela concepção de educação libertadora, os Círculos de Cultura propõem

práticas de ensinar-aprender fundadas na horizontalidade das interações pedagógicas, no diálogo e na vivência da aprendizagem como um processo ativo e partilhado de construção do saber. (BRANDÃO, 2008, p.77).

A construção do saber consiste em aprender a "dizer sua palavra” (BRANDÃO, 2008, p.77), cuja visão sintetiza os fundamentos dos Círculos de Cultura.

Tais ideias fundamentam o método de alfabetização criado por Paulo Freire, o qual representa uma crítica ao método de ensino tradicional. Segundo Fiori

o método Paulo Freire não ensina a repetir palavras, não se restringe a desenvolver a capacidade de pensá-las segundo as exigências lógicas do discurso abstrato; simplesmente coloca o alfabetizando em condições de poder re-existenciar criticamente as palavras de seu mundo, para, na oportunidade devida, saber e poder dizer a sua palavra. (FIORI apud FREIRE, 2014, p. 17).

O método compreende uma proposta de alfabetização de adultos em contrapartida ao método de alfabetização fundado em meios de memorização de palavras soltas, com a repetição de palavras e o uso de cartilhas. Propõe, portanto, a identificação de palavras-chave do vocabulário dos alunos, chamadas de palavras geradoras, que se originam a partir da realidade dos educandos. 
A busca das palavras geradoras decorre de três etapas. A primeira é a etapa de investigação, que se refere à busca conjunta entre educador e educando das palavras mais significativas da sua realidade. A segunda etapa é a de tematização, que é o momento da tomada de consciência de mundo por parte do aluno, através da análise do significado social de temas e palavras. E a terceira etapa é a de problematização, quando o professor desafia e inspira o aluno a adquirir uma visão crítica do mundo para uma proposta de conscientização.

Assim, nota-se a interação entre a realidade do educando e o método de ensino, cuja relação é fundamental para a construção significativa do conhecimento. Acerca disso, Freire afirma que a alfabetização de adultos é vista por ele como um ato político, um ato de conhecimento, de forma que constitui um ato criador (FREIRE, 2011). Isso porque

seria impossível engajar-se num trabalho de memorização mecânica dos ba-be-bibo-bu, dos la-le-li-lo-lu. Daí também não pudesse reduzir a alfabetização ao ensino puro da palavra, das sílabas ou das letras. Ensino em cujo processo o alfabetizador fosse 'enchendo' com suas palavras as cabeças supostamente 'vazias' dos alfabetizandos. Pelo contrário, [...] o processo da alfabetização tem, no alfabetizando, o seu sujeito. (FREIRE, 2011, p. 28, grifo do autor).

Nessa perspectiva, percebe-se que a prática educativa está atrelada ao diálogo, à comunicação entre os sujeitos na busca de significação e de significados, ao contrário de apenas transmissão de saberes. Na visão freiriana, é dessa relação dialógica entre os sujeitos e o mundo que se dá a educação libertadora, também conceituada como educação problematizadora e transformadora. Ratificando isso, Freire diz que "a educação problematizadora se faz, assim, um esforço permanente através do qual os homens vão percebendo, criticamente, como estão sendo no mundo com que e em que se acham" isso porque "não é possível entendê-los fora de suas relações dialéticas com o mundo" (FREIRE, 2014, p. 100, grifo do autor).

Em contraponto, Freire define o método tradicional de ensino como educação bancária na qual o educador é o centro nesse processo. Acerca disso, o autor explica que

'na concepção 'bancária' que estamos criticando, para a qual a educação é o ato de depositar, de transferir, de transmitir valores e conhecimentos, não se verifica nem pode verificar-se esta superação. Pelo contrário, refletindo a sociedade opressora, sendo dimensão da 'cultura do silêncio', a educação bancária mantém e estimula a contradição. (FREIRE, 2014, p. 82, grifo do autor).

Em face da visão de educação libertadora, busca-se refletir a importância do ensino de língua portuguesa nos espaços prisionais no sentido de promover o uso da linguagem como prática de liberdade. E como se pode fazê-lo? Em Educação na cidade é abordada essa questão, como se pode ver: 
Não é possível discutir linguagem sem discutir poder, sem pensar as classes sociais e suas contradições. [...] É fundamental a identidade cultural, que passa pela luta de classe, dos educandos. O respeito, por isso mesmo, à sua sintaxe, à sua semântica. E é isso que não ocorre entre nós quando desconsideramos ou mal consideramos o discurso dos meninos e das meninas pobres. [...] Temos, na verdade, que respeitar a linguagem popular tanto quanto temos que respeitar o conhecimento das classes populares para, com elas, ir além de. A linguagem é culturalmente um dos importantes aspectos do processo de democratização das sociedades. (FREIRE, 2005, p. 137- 139).

Diante disso, entende-se que ensinar língua portuguesa é propiciar aos educandos a compreensão da linguagem como forma de interação social, de forma que o ensino da língua esteja voltado para sua realidade; é compreender que a palavra nunca é neutra, mas representa uma luta de classes (BAKHTIN, 2009).

Todavia, o que se observa é a ênfase à gramática normativa no ensino de língua portuguesa na escola, cujo objetivo é dar condições para o educando ter acesso ao conhecimento da norma culta, ou seja, para que ele aprenda a escrever corretamente, através de técnicas de codificação e decodificação do código escrito. Nesse viés, percebe-se que o ensino de português relaciona-se estritamente à língua e não à linguagem, corroborando com a percepção de que grande parte dos educadores apresenta uma visão equivocada sobre o que é e para que serve o ensino de língua portuguesa na escola.

A respeito disso, Freire comenta que

é preciso que a educação esteja - em seu conteúdo, em seus programas e em seus métodos - adaptada ao fim que se persegue: permitir ao homem chegar a ser sujeito, construir-se como pessoa, transformar o mundo, estabelecer com os outros homens relações de reciprocidade, fazer a cultura e a história [...] uma educação que liberte, que não adapte, domestique ou subjugue. (FREIRE, 2005, p. 45).

Em face do exposto, reitera-se que o objetivo da educação nas prisões, de forma mais específica, do ensino de língua portuguesa, é de promover o reconhecimento do valor do que se aprende na escola para a ascensão social dos presos, cuja realidade é marcada pela opressão, pela desumanização.

Partindo do princípio que "com a palavra, o homem se faz homem", assumindo “conscientemente sua essencial condição humana" (FREIRE, 2014, p. 17), este artigo propõe o ensino de língua portuguesa fundamentado nos estudos desenvolvidos por Mikhail Bakhtin. Isso porque sua teoria dialógica corrobora com a percepção de Paulo Freire sobre construção do sujeito pela linguagem e uso da linguagem como forma de interação social e de libertação.

\section{A linguagem como interação social na perspectiva bakhtiniana}


Na perspectiva dos estudos desenvolvidos por Mikhail Bakhtin sobre a linguagem, a língua é entendida como dinâmica e a enunciação como ato concreto da interação social entre os interlocutores, que apresentam atitudes ativas responsivas em um dado momento histórico. Sob esse prisma,

\begin{abstract}
'o locutor serve-se da língua para suas necessidades enunciativas concretas', já que as formas linguísticas ganham sentido no uso. [...] Desse modo, na constituição do ponto de vista do locutor em um dado contexto social de enunciação, a forma linguística interessa como signo ideológico, variável e flexível, e não como sinal estável. A relação entre signo ideológico, que não só reflete, mas também refrata uma dada realidade, e sinal, para Bakhtin/Volochinov, corresponde à tensa relação entre instabilidade e estabilidade, constitutiva da atividade da linguagem. (BARBISAN; DI FANTI, 2010, p.08, grifo das autoras)
\end{abstract}

Na teoria bakhiniana, a enunciação é constituída por enunciados, sendo "real unidade da comunicação discursiva" (BAKHTIN, 2003, p. 274, grifo do autor). O enunciado apresenta singularidades, tais como: alternância dos sujeitos do discurso, conclusibilidade e formas estáveis de gênero. Segundo Bakhtin (2003, p. 279-280), a alternância dos sujeitos "emoldura o enunciado e cria para ele a massa firme, rigorosamente delimitada dos outros enunciados a ele vinculados", distinguindo unidade discursiva de unidade da língua. A conclusibilidade compreende uma forma de alternância entre os sujeitos do discurso, na medida em que um falante já disse ou escreveu tudo o que desejava em um determinado momento, possibilitando que outro sujeito assuma posição responsiva. Por fim, as formas estáveis de gênero representam a vontade discursiva do falante que se realiza primeiramente na escolha de um tipo de discurso.

Portanto, pode-se reconhecer que os estudos enunciativos desenvolvidos pelo Círculo de Bakhtin definem o discurso como objeto de estudo da linguística, tendo como princípio o caráter dialógico da linguagem, que se fundamenta na permanente relação entre os interlocutores da enunciação. Ratificando isso, cabe destacar o pensamento bakhtiniano enunciativo de que

a verdadeira substância da língua não é constituída por um sistema abstrato de formas linguísticas nem pela enunciação monológica isolada, nem pelo ato psicofisiológico de sua produção, mas pelo fenômeno social da interação verbal, realizada através da enunciação ou das enunciações. [...] O diálogo, no sentido estrito do termo, não constitui, é claro, senão uma das formas, é verdade que das mais importantes, da interação verbal. Mas pode-se compreender a palavra 'diálogo' num sentido amplo, isto é, não apenas como a comunicação em voz alta de pessoas colocadas face a face, mas toda comunicação verbal, de qualquer tipo que seja. (BAKHTIN, 2009, p. 127, grifo do autor). 
Por conseguinte, entende-se que, para o autor, a linguagem é uma forma de interação social, cujo objetivo é comunicar. Nesse sentido, o diálogo como produto de trocas sociais, produzido pela situação social mais imediata e pelo meio social mais amplo, constitui a estrutura da enunciação. A enunciação reflete as condições de vida de uma determinada comunidade linguística, enfatizando, assim, o caráter histórico-social e ideológico da linguagem.

O dialogismo, um dos conceitos-chave da Teoria do Discurso de Bakhtin, emerge da palavra diálogo, cujo conceito não está associado às significações sociais de uso comum (interação face a face, com troca de turnos entre os participantes), mas "às relações entre réplicas do diálogo concreto", cujo espaço se apresenta como um complexo de forças que atua no diálogo e condiciona a forma e as significações das vozes sociais (FARACO, 2009, p. 40). Através da dialogismo é que o sujeito se constitui, uma vez que a realidade linguística se apresenta para ele como um universo de vozes sociais nas mais variadas relações dialógicas. Sendo assim, o sujeito, assimilando as múltiplas vozes, vai constituindo a si mesmo e as suas inter-relações dialógicas.

De acordo com Faraco (2009, p. 54, grifo do autor), nas relações dialógicas os signos "refletem e refratam o mundo", na medida em que "refratar significa, aqui, que com nossos signos nós não somente descrevemos o mundo, mas construímos [...] diversas interpretações (refrações) desse mundo". Por conseguinte, compreende-se que o sujeito, de qualquer forma, sempre acaba demonstrando sua posição diante da realidade, sendo impossibilitado de imparcialidade. Em seu discurso, o sujeito exterioriza as múltiplas vozes sociais que o constitui a partir de sua singularidade.

Em Questões de Literatura e Estética, Bakhtin, p. diz que a palavra da língua é "semialheia", tornando-se própria no instante em que o falante "a povoa com sua intenção, com seu acento, quando a domina através do discurso, torna-a familiar com a sua orientação semântica e expressiva” (BAKHTIN, 1993, p. 100). Isso significa dizer que, é na interação verbal que os signos assumem sentidos, que não estão presos no sistema semântico abstrato, porém são constituídos na história e nas experiências dos grupos humanos, completos de contradições e confrontos de valorações e interesses sociais.

Partindo do pressuposto de que as relações dialógicas são sempre de carácter social, é essencial dimensionar os sujeitos como estrutura socioideológica, organizados em um complexo quadro de relações socioculturais. Portanto, é através de tal organização que surgem as esferas discursivas que marcam a posição de um sujeito social, caracterizando os índices sociais de valor que constituem o encontro de posições avaliativas no discurso. 


\subsection{Os gêneros discursivos}

O estudo dos gêneros é muito antigo, marcando seu início com Platão e, depois, firmando-se com Aristóteles, com foco nos gêneros literários. Atualmente, os estudos sobre gêneros apresentam uma perspectiva diferente da aristotélica, focalizando a análise do texto e do discurso através da descrição da língua e da visão social, a fim de compreender a natureza sociocultural no uso da língua de modo geral.

Para Bakhtin, os gêneros estão relacionados à enunciação. A enunciação entendida por Bakhtin compõe-se de enunciados, sejam orais ou escritos, através do emprego da língua pelos falantes. Consoante Brait e Melo (2005), nessa perspectiva, os enunciados representam unidades de significação, necessariamente contextualizados. Esses enunciados exprimem condições e finalidades específicas de cada campo da esfera comunicativa, refletindo as estruturas sociais recorrentes e típicas de cada cultura. Esses tipos "relativamente estáveis de enunciados", foram denominados por Bakhtin como "gênero do discurso" (BAKHTIN, 2003, p. 262, grifo do autor).

Os gêneros discursivos são relativamente estáveis porque acompanham a evolução do tempo, constituem-se historicamente, podendo sofrer alterações conforme as mudanças no discurso das pessoas e na sua relação com a esfera social em uso. Na perspectiva bakhtiniana, tal esfera refere-se à atividade humana, não como um princípio de classificação de textos, mas como indicação de instâncias discursivas, como discurso jurídico, discurso religioso, etc.

Nas práticas discursivas, pode ser identificado um conjunto de gêneros textuais que, às vezes, são próprios ou específicos como práticas ou rotinas comunicativas institucionalizadas e instauradoras de relações de poder. No entanto, de acordo com Marcuschi (2003), os gêneros não são instrumentos estanques e limitadores da ação criativa, de modo que podem adaptar-se através das possibilidades de uso social.

A identificação de um gênero se dá, principalmente, através do uso e da finalidade, porém existe certo padrão de organização interna que torna a classificação mais prática. A organização interna caracteriza-se por elementos que atribuem índices de valor que dão sentido aos enunciados, que são: conteúdo temático, estrutura composicional e estilo. O conteúdo temático ou tema compreende o domínio de sentido do qual trata o gênero. É um modo particular de orientação na realidade, um primeiro nível de refração da realidade: a avaliação social (os modos de ver) e a relação com o interlocutor são fatores essenciais ao tema do gênero (GRILLO, 2006). A estrutura composicional compreende os elementos das estruturas comunicativas e semióticas compartilhadas pelos textos pertencentes ao gênero; 
refere-se ao modo de organização dos elementos textuais, cuja composição mostra a estrutura própria de cada gênero discursivo.

O estilo compreende o modo particular de como o tema será tratado, isto é, representa os graus de formalidade e valoração do autor do texto. É uma seleção de meios linguísticos e enunciativos em função da imagem do interlocutor e de como se presume sua compreensão responsiva ativa do enunciado. De acordo com Bakhtin (2003, p. 268) "onde há estilo, há gênero". Isso porque "a passagem do estilo de um gênero para outro não só modifica o som do estilo nas condições do gênero que não lhe é próprio como destrói ou renova tal gênero" (BAKHTIN, 2003, p. 268).

A escolha do gênero não é de livre vontade do falante, pois vai depender da finalidade social do discurso, exigindo um processo de seleção do tipo de linguagem, da situação de uso e da relação social entre os interlocutores, obedecendo, assim, os hábitos culturalmente construídos.

\section{O ensino de Língua Portuguesa através dos gêneros discursivos}

Os gêneros discursivos surgem como proposta de ensino no Brasil por volta dos anos 90, nos Parâmetros Curriculares Nacionais (PCN). Os PCN de Língua Portuguesa para o Ensino Fundamental propõe à escola a função de promover o estudo dos gêneros, considerando os variados níveis de conhecimento prévio dos educandos. Com relação aos anos finais do Ensino Fundamental, os PCN orientam que, no trabalho com os conteúdos previstos nas diferentes práticas, a escola organize um conjunto de atividades que possibilitem ao aluno desenvolver o domínio linguístico oral e escrito em situações de uso público da linguagem, considerando a situação de produção social e material do texto, operando sobre as dimensões pragmática, semântica e gramatical.

Não obstante, nota-se que, geralmente, a "identificação clássica de gêneros narração, descrição e dissertação" permanecem como centro das práticas de ensino de língua portuguesa (BIASI-RODRIGUES, 2008, p. 33). De acordo com Marcuschi (2003), tais práticas não constituem um trabalho com gêneros textuais, todavia com tipos textuais. A expressão "tipo textual" é usada "para designar uma espécie de sequência teoricamente definida pela natureza linguística de sua composição (aspectos lexicais, sintáticos, tempos verbais, relações lógicas)", que, geralmente, "abrangem cerca de meia dúzia de categorias conhecidas como: narração, argumentação, exposição, descrição, injunção" (MARCUSCHI, 2003, p. 22 grifo do autor). 
$\mathrm{Na}$ visão de outros autores, como Charaudeau e Bonini, a descrição, dissertação e narração representam formas de organização do discurso, "tipos textuais ou modos enunciativos de organização do discurso no texto". Não são elementos de comunicação, porém “fórmulas abstratas" (apud LOPES-ROSSI, 2002, p. 22). Com isso, entende-se que os gêneros textuais ou gêneros do discurso é que são reconhecidos pelos usuários da língua como objeto de interação, não os tipos textuais.

De acordo com Lopes-Rossi (2002), o ensino de língua, centrado nos tipos textuais, torna-se comprometido por vários fatores, tais como:

artificialidade das situações de redação, pois o texto produzido na escola (a redação) não é um texto autêntico, não existe na nossa vida social, não tem finalidade a não ser cumprir uma exigência do professor ou do programa de ensino; artificialidade dos temas propostos ou pouca possibilidade de interesse dos alunos nesses temas; falta de objetivos de escrita por parte dos alunos, a não ser tirar nota [...]; falta de um real leitor (exceto o professor) [...]. (LOPES-ROSSI, 2002, p.20).

Além disso, nesses tipos de produção textual, Lopes-Rossi (2002) salienta que o professor não acompanha o estudante nas várias etapas de elaboração do texto, ou nem existam etapas de planejamento, organização de ideias e revisão do texto por parte dos estudantes.

Outro aspecto importante que deve ser salientado no ensino de língua é o desenvolvimento dos conhecimentos referentes ao léxico e à estrutura da língua. $\mathrm{Na}$ perspectiva dos estudos da enunciação de Bakhtin (2009), o desenvolvimento das categorias gramaticais também deve ocorrer no discurso. Para ele, tanto as categorias morfológicas quanto as sintáticas só tem sentido no interior da enunciação. Bakhtin explica que "se ficarmos nos limites das categorias gramaticais efetivas da linguística contemporânea, jamais poremos a mão sobre a inacessível enunciação completa" (BAKHTIN, 2009, p. 147). Isso porque as categorias gramaticais direcionam o ensino para o sistema abstrato da língua, afastando o do discurso.

Os PCN também apontam a importância dos aspectos gramaticais no interior da enunciação, como se pode ver:

É no interior da situação de produção de texto, enquanto o escritor monitora a própria escrita para assegurar sua adequação, coerência, coesão e correção, que ganham utilidade os conhecimentos sobre os aspectos gramaticais. Saber o que é substantivo, adjetivo (...), etc. não significa ser capaz de construir bons textos, empregando bem esses conhecimentos. (...) Isso não significa dizer que não é para ensinar fonética, morfologia ou sintaxe, mas que elas devem ser oferecidas à medida que se tornarem necessárias para a reflexão sobre a língua. (PARÂMETROS CURRICULARES NACIONAIS, 2000, p.90)

A fim de contribuir na melhoria das práticas pedagógicas acerca do ensino de língua 
materna, Lopes-Rossi orienta que o professor crie "projetos pedagógicos que visem ao conhecimento, à leitura, à discussão sobre o uso e as funções sociais dos gêneros" que sejam pertinentes à produção escrita e circulação social (LOPES-ROSSI, 2002, p. 30).

Após tais considerações, observa-se que as práticas educativas voltadas ao ensino de língua portuguesa, comumente desenvolvidas na escola, não estão vinculadas às situações reais da vida, tornando a sala de aula um ambiente pouco atraente para os educandos. De maneira mais específica, percebe-se que essas práticas são menos atraentes ainda aos educandos privados de liberdade, uma vez que a educação não ocupa um lugar privilegiado no espaço intramuros. Certamente, isso se deve à valorização dos tipos textuais nas aulas de Língua Portuguesa, ao invés da valorização dos gêneros.

\section{Considerações finais}

Este artigo buscou promover uma discussão sobre a importância do ensino de língua portuguesa na Educação de Jovens e Adultos nos espaços prisionais a partir de práticas educativas que valorizem o uso da linguagem como ação libertadora. A escolha do tema deuse em virtude do importante papel da educação como um meio de ressocialização dos indivíduos privado de liberdade, o que resulta na incessante busca por alternativas para recondução destes aos bancos escolares.

Apesar dos esforços que se tem dedicado ao longo dos anos para a garantia e a qualidade da educação no âmbito prisional, seja através da criação de leis, resoluções ou políticas públicas, constata-se, através das pesquisas, que a escola é um lugar pouco valorizado entre os presos, o que talvez possa estar atrelado aos modelos tradicionais de ensino. A educação, principalmente nos espaços prisionais, deve significar uma possibilidade para que o indivíduo reconheça-se como um sujeito de transformação da própria realidade. Nesse sentido, este estudo aponta o ensino de língua portuguesa a partir da visão do uso da linguagem como prática de liberdade e de interação social.

As reflexões sobre educação abordadas no artigo giram em torno do ensino de língua portuguesa por se compreender que o uso da linguagem representa o fio condutor para o sucesso na construção de conhecimentos e na formação da cidadania dos indivíduos. Diante disso, foi enfatizada a relevância do trabalho com gêneros discursivos nas aulas de português, pois representa a prática de formas de comunicação em situações reais de vida, promovendo a valorização do que se aprende ao que, de fato, se utiliza nas interações sociais do cotidiano. 
Tal perspectiva emergiu dos estudos sobre linguagem desenvolvidos por Bakhtin, do qual resultou sua teoria dialógica.

Debruçando-se sobre os estudos bakhtinianos, observou-se a existência de certa interdiscursividade entre a teoria dialógica e a concepção libertadora de educação proposta por Paulo Freire. Isso porque ambas reconhecem o valor da linguagem para a formação do sujeito. Também, apontam o diálogo como um espaço de construção de identidade, onde a palavra é povoada de intenções, configurando uma luta de classes sociais.

A educação libertadora de Freire propõe isto: uma educação que valorize o diálogo, as relações sociais, que desperte a consciência do indivíduo sobre a sua capacidade de pensar, de criar, de existir no mundo e transformar este. Em face disso, entende-se, portanto, que as práticas educativas de ensino de português através dos gêneros discursivos contribuem para o uso da linguagem como ação libertadora. Isso porque representa uma possibilidade de ensino que aproxima o educando da sua realidade, considerando suas experiências de vida, diferentemente dos métodos de memorização e de decodificação ainda tão utilizados.

Promover uma educação libertadora em um espaço prisional não parece uma tarefa fácil, tendo em vista a dicotomia que envolve tal relação. Contudo, é mister que a escola sirva de mediação para que a situação de prisão/opressão mude para a de libertação na vida do indivíduo privado de liberdade. De maneira concreta, isso é possível através de práticas educativas que valorizem sua história e respeitem sua cultura, viabilizando a esse indivíduo um ensino que atenda suas necessidades.

As atividades propostas a partir dos gêneros discursivos apresentadas neste trabalho representam algumas das possibilidades de desenvolver a leitura, a escrita e também os elementos gramaticais, que geralmente recebem maior destaque nas aulas de língua. Por meio de atividades como essas podem desenvolvidas todas as habilidades linguísticas do educando, sem que para isso ele seja submetido a uma aula monótona e desinteressante. Diante disso, espera-se ter contribuído para o surgimento de novas metodologias de ensino de português na EJA prisional, enfatizando, assim, a relevância do trabalho com gêneros discursivos para a ascensão do uso da linguagem como prática libertadora.

\section{Referências}

BAKHTIN, Mikhail. Marxismo e filosofia da linguagem. 13 Ed. São Paulo: Editora Hucitec, 2009. 
BARBISAN, Leci B.; DI FANTI, Maria da Glória. Estudos da enunciação: bases epistemológicas e perspectivas atuais. In. Cadernos de pesquisas em linguística: estudos da enunciação. Porto Alegre, vol. 5, número 1, p. 05-25, novembro de 2010.

BEZERRA, Maria A. Ensino de língua portuguesa e contextos teórico-metodológicos. In. DIONÍSIO, Angela P. [Et al]. Gêneros textuais e ensino. São Paulo: Parábola Editorial, 2010.

BIASI-RODRIGUES; Bernardete. A abordagem dos gêneros textuais no ensino da Língua Portuguesa. In. PONTES; Antônio L; COSTA; Maria Aurora R. Ensino de Língua Materna na perspectiva do discurso. 1 Ed. Fortaleza: Edições Demócrito Rocha, 2008.

BRAIT; Beth; MELO, Rosineide de. Enunciado/enunciado concreto/enunciação. In. BRAIT; Beth. Bakhtin: conceitos-chave. 2 Ed. São Paulo: Contexto, 2005.

BRANDÃO, Carlos R. Círculo de Cultura. In. In. STRECK, Danilo R. [Et al]. Dicionário Paulo Freire. Belo Horizonte: Autêntica Editora, 2008.

BRASIL. Constituição da República Federativa do Brasil de 05 de outubro de 1988. - 35 Ed. - $\quad 2012 . \quad$ Drasília: em: file://C:/Users/piloto/Downloads/constituicao_federal_35ed.pdf Acesso em: 17.08.2015.

BRASIL/MINISTÉRIO DA JUSTIÇA. Levantamento Nacional de Informações Penitenciárias - INFOPEN - junho de 2014. Disponível em: http://www.justica.gov.br/noticias/mj-divulgara-novo-relatorio-do-infopen-nesta-tercafeira/relatorio-depen-versao-web.pdf Acesso em 20.09.2015.

BRASIL. Lei de Execução Penal $n^{o} 7.210$ de julho de 1984. Disponível em: http://www.planalto.gov.br/ccivil_03/LEIS/L7210.htm Acesso em 24.08.2015.

BRASIL. Lei $n^{o}$ 12.433, de 29 de junho de 2011. Disponível em: http://www.planalto.gov.br/ccivil_03/_ato2011-2014/2011/lei/112433.htm Acesso em 26.08 .2015

BRASIL/MINISTÉRIO DA EDUCAÇÃO. Diretrizes Curriculares da Educação Básica. Brasília: MEC, SEB, DICEI, 2013.

BRASIL/MINISTÉRIO DA EDUCAÇÃO. Lei de Diretrizes e Bases da Educação Nacional $n^{o}$ 9.394, de 20 de dezembro de 1996. Disponível em: http://portal.mec.gov.br/arquivos/pdf/ldb.pdf Acesso em: 17.08.2015.

BRASIL/MINISTÉRIO DA EDUCAÇÃO. Parâmetros Curriculares Nacionais: língua portuguesa/ Secretaria de Educação Fundamental. - 2 Ed. - Rio de Janeiro: DP\&A, 2000.

BRASIL/MINISTÉRIO DA EDUCAÇÃO. Resolução nº 4, de 13 de julho de 2010. In. BRASIL/MINISTÉRIO DA EDUCAÇÃO. Diretrizes Curriculares da Educação Básica. Brasília: MEC, SEB, DICEI, 2013.

FARACO, Carlos Alberto. Linguagem \& diálogo: as ideias linguísticas do círculo de Bakhtin. São Paulo: Parábola Editorial, 2009. 
FREIRE, Paulo. A importância do ato de ler: em três artigos que se completam. - 51 Ed. São Paulo: Cortez, 2011.

. Educação na cidade. - 6 Ed. - São Paulo: Cortes, 2005.

Paz e Terra, 2003.

Pedagogia da autonomia: saberes necessários à prática educativa. São Paulo: . Pedagogia do Oprimido. - 58 Ed. - Rio de Janeiro: Paz e Terra, 2014.

. Educação como prática de liberdade. Rio de Janeiro: Paz e Terra, 1967.

GRILLO, S.V. de C. Esfera e Campo. In: BRAIT, Beth. Bakhtin: outros conceitos - chave. São Paulo: Contexto, 2006.

OLIVEIRA, Avelino da Rosa. Oprimido/opressor. In. STRECK, Danilo R. [Et al]. Dicionário Paulo Freire. Belo Horizonte: Autêntica Editora, 2008.

PORTAL BRASIL - EDUCAÇÃO. Levantamento mostra escolaridade dos presidiários no País. Disponível em http://www.brasil.gov.br/educacao/2012/04/levantamento-mostraescolaridade-dos-presidiarios-no-pais Acesso em: 16.08. 2015.

JUSBRASIL. Perfil dos presos no Brasil em 2012. Disponível em: http://professorlfg.jusbrasil.com.br/artigos/121932332/perfil-dos-presos-no-brasil-em-2012

Acesso em 23.08.2015.

LOPES-ROSSI, Maria A. G. Gêneros discursivos no ensino de leitura e produção de textos. 1 Ed. - Taubaté, SP: Cabral Editora e Livraria Universitária, 2002.

MARCUSCHI, Luiz A. Gêneros textuais: definição e funcionalidade. In: DIONÍSIO, Angela P.; MACHADO, Anna R.; e BEZERRA, Maria A. Gêneros textuais e ensino. 2 Ed. Rio de Janeiro: Lucerna, 2003.

MARCUSCHI, Luiz Antônio. Produção textual, análise de gêneros e compreensão. São Paulo: Parábola Editorial, 2008.

SESI/UNESCO. Conferência Internacional sobre Educação de Adultos (V; 1997; Hamburgo; Alemanha) Declaração de Hamburgo: Agenda para o futuro. - Brasília: SESI/UNESCO, 1999. Disponível em: http://unesdoc.unesco.org/images/0012/001297/129773porb.pdf Acesso em: 24.08.2015. 